ANUARIO DE ESTUdIOS MEDIEVALES

50/2, julio-diciembre de 2020, pp. 665-695

ISSN 0066-5061

https://doi.org/10.3989/aem.2020.50.2.02

\title{
LOS CENTROS ESCRIPTORIOS EN EL REINO DE LEÓN Y CASTILLA: LA TRANSICIÓN DE LA VISIGÓTICA A LA CAROLINA A TRAVÉS DE LA ESCRITURA EPIGRÁFICA*
}

\author{
PLACES OF WRITING IN THE KINGDOM OF LEON-CASTILE: \\ THE TRANSITION FROM VISIGOTHIC SCRIPT TO CAROLINE MINUSCULE \\ THROUGH EPIGRAPHIC SCRIPT
}

\author{
MARÍA ENCARNACIÓN MARTÍN LÓPEZ \\ Universidad de León \\ https://orcid.org/0000-0002-3357-3855
}

\begin{abstract}
Resumen: Este es un estudio de la evolución de la escritura epigráfica de transición (XI-XIII) y su producción al amparo de los principales centros escriptorios de León y Castilla, donde la escritura carolina se introduce en el siglo XI aunque no tendrá un desarrollo pleno hasta el siglo XII. Veremos la pervivencia de las formas visigóticas en los diferentes núcleos, ya sean urbanos o rurales, así como la simultaneidad de dos, e incluso, tres alfabetos en un mismo tiempo y lugar.
\end{abstract}

Palabras clave: epigrafía medieval; paleografía; cultura gráfica; centros escriptorios; visigótica; carolina; gótica.

Abstract: This is a study on the evolution of transitional epigraphic writing ( $11^{\text {th }}$ to $13^{\text {th }}$ centuries $)$ and its production in the context of the main centres of written production in Leon-Castile, where Caroline minuscule was introduced in the $11^{\text {th }}$ century, but was not to be fully developed until the $12^{\text {th }}$. The survival of Visigothic script forms in the different nuclei, whether urban or rural, will be analysed as well as the simultaneous use of two and even three alphabets at the same time and place.

Keywords: medieval epigraphy; palaeography; graphic culture; places of writing; Visigothic script; Caroline minuscule; Gothic script.

\section{SUMARIO}

1. Introducción.- 2. La escritura visigótica publicitaria. Señas de identidad.- 3. La transición en los centros monásticos.- 4. La transición gráfica en las inscripciones.4.1. Burgos.- 4.2. Zamora.- 4.3. Cantabria.- 4.4. Asturias.- 4.5. Orense.- 5. Conclusión.- 6. Figuras.- 7. Bibliografía citada.

\footnotetext{
* Este estudio ha sido posible gracias al Proyecto de Investigación del Ministerio de Economía y Competitividad HAR2016-76310-R, con ayuda de los fondos europeos FEDER.

Citation / Cómo citar este artículo: Martín López, María Encarnación (2020), Los centros escriptorios en el reino de León y Castilla: la transición de la visigótica a la carolina a través de la escritura epigráfica, "Anuario de Estudios Medievales" 50/2, pp. 665-695. https://doi.org/10.3989/aem.2020.50.2.02

Copyright: (C) 2020 CSIC. Este es un artículo de acceso abierto distribuido bajo los términos de la licencia de uso y distribución Creative Commons Reconocimiento 4.0 Internacional (CC BY 4.0).
} 


\section{INTRODUCCIÓN}

El epígrafe, como un objeto escrito más, presenta una cronología similar a la escritura de los libros y códices. Esto no es una novedad, toda vez que Jean Mallon, en su obra de 1952, estableciera que no existe más que una escritura independientemente del soporte sobre el cual se ejecute ${ }^{1}$. Los elementos que configuran la escritura visigótica libraria y documental, sea redonda o cursiva, son bien conocidos y reconocidos. Los estudios realizados en los últimos años sobre documentación y las recientes ediciones críticas de los códices visigóticos han iluminado y ampliado notablemente el conocimiento de la visigótica en estos soportes ${ }^{2}$. No sucede así en el ámbito epigráfico, donde los estudios paleográficos llevan un recorrido más corto. Ciertamente, las investigaciones a principios del siglo XX se centraron en la epigrafía visigoda y en la epigrafía llamada cristiana de los siglos VIII al $\mathrm{X}^{3}$ pero sesgadas por un análisis textual y formal, sin una crítica paleográfica. Será Navascués quien dé un toque de atención a la necesidad de un estudio integral del epígrafe ${ }^{4}$. No obstante, habrá que esperar a 1982 cuando García Lobo precise las características y evolución de la escritura en las inscripciones a través de su estudio monográfico sobre San Miguel de Escalada (León) ${ }^{5}$. A partir de este trabajo, el interés por la epigrafía medieval irá creciendo. La elaboración de un corpus de inscripciones como herramienta de trabajo resulta imprescindible para el conocimiento de estas fuentes, tarea emprendida en 1995 por García Lobo en el marco del proyecto I+D Corpus Inscriptionum Hispaniae Mediaevalium (CIHM) con sede en el Instituto de Estudios Medievales de la Universidad de León y continuada actualmente por un grupo de investigadores de España, Italia, Francia y Portugal adscritos al proyecto ${ }^{6}$. Gracias a estas fuentes editadas

${ }^{1}$ Mallon 1952. En este mismo sentido, en el ámbito romano contamos con la obra de Gordon (1957). Banti 1995, p. 34 incide en la necesidad de la paleografía para el estudio de la epigrafía medieval.

${ }^{2}$ Dada su extensión, no podemos detallar aquí la bibliografía sobre este tema. Sin embargo y a modo de ejemplo debemos destacar algunas iniciativas cercanas en el tiempo como la llevada a cabo por el Seminario de Paleografía de la Universidad Autónoma de Barcelona (véase Alturo, Torras, Castro 2012).

${ }^{3}$ Vives 1942; Gómez Moreno 1966. Los estudios en torno a la escritura visigoda son revisados por Velázquez 2000.

${ }^{4}$ Navascués 1953. Su aportación para el desarrollo moderno de la epigrafía ha sido destacada en numerosas ocasiones (véase García Lobo 2001; De Santiago 2004).

${ }^{5}$ García Lobo 1982.

${ }^{6}$ Recientemente, Irene Pereira (2017) ha hecho un completo repaso por la andadura de la epigrafía medieval en España, que en los últimos años ha experimentado un auge sin precedentes. Los volúmenes editados son: Burgos (2016) por Alejandro García Morilla; Salamanca (2017) por Natalia Rodríguez Suárez; Valladolid (2017) por Francisco Molina de la Torre; Gua- 
y a los distintos artículos publicados en los últimos años ${ }^{7}$ podemos contar con datos novedosos que darán una perspectiva nueva a la epigrafía.

La escritura visigótica tiene como nexo con la romanidad la escritura visigoda; el continuismo con la escritura epigráfica de la Antigüedad clásica es una evidencia ${ }^{8}$. En el siglo VIII encontramos ya definidos los elementos gráficos de la escritura visigótica que tendrán un largo recorrido hasta bien entrado el siglo XIII. Esta cronología no está exenta de precisiones, pero preferimos una periodización amplia para determinar la pervivencia de la visigótica dadas las diferencias cronológicas existentes entre los distintos territorios hispanos. En general, esta escritura convivió con la carolina hasta los albores del goticismo, momento de su definitiva desaparición. Por tanto, anticipamos que la convivencia entre ambas grafías llevará a una contaminación mutua en una extensión territorial y cronológica mucho más amplia de lo que hasta ahora se viene admitiendo?

Para seguir con las precisiones de concepto debemos diferenciar dos modalidades básicas de visigótica, la llamada "elegante" y la "cursivizada" ${ }^{10}$, modalidades que conviven en el tiempo y en el espacio. Algunos autores han intentado relacionar los caracteres elegantes con centros escritorios profesionales y la modalidad cursivizada con espacios no cultos o rurales, pero la línea divisoria no está clara. Así, la escritura elegante puede hallarse de forma aislada en lugares sin referentes de un centro escritorio, realizada bien por encargo bien importada. Al revés, hallamos epígrafes ejecutados con grafías cursivizadas en centros más desarrollados y con posibilidades de acceso a un taller profesional. En los últimos años del XI aparecen las primeras influencias carolinas que se manifiestan en elementos gráficos aislados como

dalajara (2018) por Javier de Santiago y José María de Francisco; Cantabria (2019) por Alberto Peña. De próxima edición: La Rioja (2019) por Irene Pereira.

${ }^{7}$ Véase Pereira 2017.

${ }^{8}$ Destacamos especialmente De Santiago 2005. Estudios cuya base se halla en el exhaustivo análisis de la escritura visigótica realizado por García Lobo 1999, 2008, quien incide en el estudio de la escritura epigráfica también en los rotuli de los códices, los íncipits y explicits con los que mantiene denominación común (estudio comparativo ya iniciado por Martín Postigo (1972), entre los títulos del Beato de Silos y la inscripción de San Frutos).

${ }^{9}$ La escritura carolina conquista el espacio librario tempranamente en el XII siendo más retardataria la desaparición de la visigótica en documentos, sobre todo, de los territorios cantábricos y de Galicia ( $c f$. Millares Carlo 1983, vol. I). La cancillería regia mantiene la escritura visigótica redonda hasta el primer tercio del siglo XII (Ruiz Albi 2003). Veremos cómo las inscripciones, dada su naturaleza conservadora, mantendrán vivas las grafías visigóticas hasta bien entrado el siglo XIII.

${ }^{10}$ Estos términos, acuñados por García Lobo (1982), serán reconocidos por el autor como poco científicos. No obstante, creemos que son descriptivos para definir la escritura cuidada, regular, de trazo preciso, en contraste con aquella realizada torpemente por manos poco expertas o con pocos medios a su alcance. 
es el uso de $V$ por $U$, la $O$ redonda por la romboidal, o la $M$ de trazos curvos, sin olvidar la exitosa introducción del sistema abreviativo carolino, como el semicolon con valor de -us para final de palabra ${ }^{11}$. Los estudios sobre el ciclo carolino introducen dos modelos gráficos: la escritura carolina o romanische kapitalis y la románica o romanische majuskel. Esta terminología utilizada en la epigrafía alemana e italiana ${ }^{12}$ no ha tenido tanto reflejo en la epigrafía hispana. Esto quizá se deba a que la carolina llega a la Península en su periodo más evolucionado, correspondiente a la llamada románica. No obstante, al ser el único modelo existente, el término "carolina" designando a la escritura formada por grafías de la capital cuadrada y de la uncial es el empleado por la mayoría de los epigrafistas, aunque se admita hablar de una carolina románica ${ }^{13}$. Geográficamente, este estudio se centrará en el territorio correspondiente al reino leonés y castellano, respectivamente, para ajustarnos mejor al espacio predeterminado de esta publicación. Además, no podemos olvidar que los epígrafes de la Cataluña conda ${ }^{14}$ y de Andalucía occidental, por poner dos casos, presentan una evolución bien diferente con particularismos gráficos que merecen una atención especial. Sería preciso la recopilación de fuentes en el territorio andaluz y comunidades murciana y valenciana para así poder aquilatar y precisar nuestras conclusiones ${ }^{15}$.

\section{LA ESCRITURA VISIGÓTICA PUBLICITARIA. SEÑAS DE IDENTIDAD}

La acepción de escritura publicitaria para la escritura epigráfica es ya común en los estudios sobre la materia. Entendemos como escritura publicitaria aquella que se utiliza especialmente para destacar, llamar la atención sobre lo escrito o parte de él, de manera que sus elementos funcionales son la notoriedad, la perdurabilidad y la universalidad. Puede resultar sorprendente el uso del término publicidad aplicado al ámbito escrito medieval. Es un concepto que no puede ni debe ser delimitado en sus connotaciones comerciales o relacionadas con la actividad económica. Pensemos en la Roma imperial donde la publicidad epigráfica tenía un sentido preciso de notoriedad. Ese

${ }^{11}$ García Morilla 2018, p. 211.

${ }^{12}$ Véase, Koch 2007, pp. 101-113; Banti 2000, pp. 61-101.

${ }^{13}$ Véase García Lobo 2002, p. 239. Francisco de Molina 2018, sin embargo, opta por el término románica por considerarlo más preciso y acorde con la realidad gráfica.

${ }^{14}$ Estudiados por De Santiago 2003, 2012.

${ }^{15}$ Actualmente, Pablo Mestre (Universidad de Sevilla) está realizando el corpus de la provincia de Sevilla. Asimismo, Rodrigo J. Fernández Rodríguez, doctorando de la Universidad Complutense de Madrid, ha iniciado el trabajo de campo para la provincia de Murcia y la de Alicante. 
carácter de llamada de atención que puede estar en todo escrito constituye en las inscripciones su propia naturaleza. En definitiva, la escritura publicitaria la hallamos en códices, en inscripciones, e incluso en documentos determinados y especiales donde su función en el conjunto escrito es llamar la atención sobre parte del texto. Armando Petrucci las denomina escrituras de aparato y las clasifica en epigráficas, o escrituras expuestas sobre materia dura, y solemnes.

Morfológicamente, la escritura visigótica es un alfabeto compuesto fundamentalmente de caracteres mayúsculos que tienen su origen en la capital clásica y en la uncial romana y al que se añaden letras minúsculas agrandadas ${ }^{16}$. Como formas significativas y características destacan la letra $A$ sin travesaño, la $H$ de tres trazos rectilíneos (el tercero corto), la $M$ de cuatro trazos convergentes hacia arriba, la $N$ cuyo trazo oblicuo tiende a la horizontalidad, la $O$ en forma oval o romboidal, la $R$ con el tercer trazo recto y corto, la $S$ de curvas poco desarrolladas y de cuerpo alargado, así como la $T$ con bucle cerrado en ojo a la izquierda. Estas grafías tienen su origen en la escritura publicitaria romana del periodo visigodo. Las inscripciones visigodas tienen la ventaja y el interés, señalan Herrero de la Fuente y Fernández Flórez, de ser trazadas por manos que gozaban de mayor libertad y variantes alfabéticas pues a las antiguas formas capitales unían las propias de las letras unciales y semiunciales ${ }^{17}$. A partir del siglo VII los trazos individualizantes de la escritura visigoda son más acusados dando lugar a unas formas alfabéticas peculiares ${ }^{18}$. El origen cronológico no se puede precisar más de momento, ni tampoco el geográfico ${ }^{19}$. Existen dos modalidades como en el ámbito documental; la elegante y la cursivizada. La primera se caracteriza por su aspecto cuidado, de trazo seguro y firme, por la regularidad del módulo en todos sus elementos, uncial y capital. La modalidad cursivizada presenta un sistema de ejecución desigual con trazos inseguros, letras de módulo irregular donde los nexos y letras inscritas apenas aparecen ${ }^{20}$. La nomenclatura utilizada para designar ambas modalidades no resulta satisfactoria ni correcta por muy expresiva que nos parezca. En busca de una alternativa terminológica, García Lobo presentó una nueva denominando a las primeras "inscripciones de cultura urbana" y a las segundas "inscripciones de cultura rural" ${ }^{21}$. No parece esta denominación mucho mejor toda vez que

\footnotetext{
${ }^{16}$ García Lobo 1979, 1982, 1999; 2008, pp. 61-92.

${ }^{17}$ Herrero de la Fuente, Fernández Flórez 2012, pp. 73-74.

${ }^{18}$ García Lobo 1999, p. 155. Sobre las características y evolución a partir de la visigoda, véase De Santiago 2005, pp. 187-215.

${ }^{19}$ No obstante, es difícil la precisión dada la dificultad de datación de muchas piezas de este periodo ( $c f$. Velázquez 2014).

${ }^{20}$ García Lobo 1982, p. 21

${ }^{21}$ García Lobo 2002, p. 248; 1999, p. 76, define como rurales aquellas que "se alejan bastante de las inscripciones de cultura urbana, tanto en su aspecto general como en sus caracteres
} 
los términos "urbano" y "rural" presentan por sí mismos problemas. No todas las inscripciones cuidadas, bien trazadas, corresponden a un entorno urbano propiamente dicho; baste que exista un monasterio con un scriptorium ${ }^{22} \mathrm{y}$, viceversa, no todas las que hallamos en espacio rural tienen que ser descuidadas o mal trazadas. Por todo ello, mantenemos la tercera vía, esto es, la que tiene en cuenta el lugar productor de la inscripción y sus condiciones materiales, físicas y culturales, de manera que clasificaríamos las inscripciones en tres grupos según el productor: inscripciones de centros profesionales, inscripciones de centros monásticos o eclesiásticos, e inscripciones de centros ocasionales ${ }^{23}$. Ya adelantamos que el conjunto epigráfico a estudiar se inscribe en aquellas realizadas en centros monásticos o eclesiásticos.

En la morfología de esta escritura debemos reseñar brevemente sus características respecto al módulo y al peso. El módulo de las letras de este alfabeto es el doble de alto que ancho, por tanto, se trata de grafías altas y estrechas que confieren al texto una apariencia estilizada. Curiosamente, el módulo no varía a lo largo de los siglos cuando, contrariamente, en la carolina y en la gótica su andadura se inicia con un módulo cuadrado que progresivamente va estrechándose y alargando la letra hasta extremos de difícil comprensión ${ }^{24}$. Respecto a su peso, éste varía de unos epígrafes a otros desde unas grafías ligeras y esbeltas, vinculadas a scriptoria epigráficos más habituados a la producción de inscripciones, a aquellas más torpes procedentes de talleres ocasionales donde la escritura es más pesada, el surco más profundo y ancho ${ }^{25}$. Llama la atención el escaso uso que se hace de los llamados recursos caligráficos -nexos, letras inscritas, cruzamientos- que serán tan recurrentes en épocas posteriores. Los ordinatores altomedievales siguen la tradición visigoda y romana de buscar ante todo claridad y legibilidad.

Esta actividad creadora, como la denominan Fernández Flórez y Herrero de la Fuente ${ }^{26}$, ya no es realizada en talleres comerciales como ocurriera

alfabéticos y en el sistema de ejecución del que desaparecen o se hacen raros los nexos y letras inscritas".

${ }^{22}$ Hablamos hace unos años de los talleres monásticos para determinar la procedencia de muchas de las piezas altomedievales (véase Martín López 2007). Irene Pereira (2019), sobre los talleres epigráficos riojanos, reafirma la importancia de los centros de producción romana con los nuevos talleres epigráficos altomedievales, todos monásticos, de manera que vemos una continuidad en la producción escrita.

${ }^{23}$ Sobre talleres epigráficos, véase Martín López 2007, pp. 203-227; García Morilla 2014, pp. 145-193; Rodríguez Suárez 2010, pp. 263-274.

${ }^{24}$ M. Gutiérrez Álvarez (1995) es el primero que hace hincapié en este fenómeno. Será estudiado con más detalle en el coloquio internacional sobre inscripciones góticas celebrado en León en 2008 ( $c f$. Martín López, García Lobo 2010).

${ }^{25}$ Martín López 2007.

${ }^{26}$ Herrero de la Fuente, Fernández Flórez 2012, p. 69. 
en la Hispania romana y visigoda ${ }^{27}$; ahora la producción se centra en el ámbito eclesiástico, en los monasterios e iglesias, como una actividad más que engloba el término scriptorium en un sentido amplio ${ }^{28}$. Este espacio común para la producción de lo escrito queda patente en la conexión entre las inscripciones, los libros y los documentos que se refleja en similitudes y transferencias de elementos gráficos en los tres soportes y que se mantendrá constante a lo largo de toda la Edad Media ${ }^{29}$. Y serán precisamente los caracteres internos y externos de las inscripciones visigóticas los que revelen los datos sobre los centros de producción -scriptoria- en las etapas iniciales de los siglos VIII al $\mathrm{X}^{30}$. Podemos pensar que las inscripciones que se producen en los centros jalonados a lo largo y ancho de la Meseta y el norte cantábrico siguen una línea, tienen un conocimiento de lo que se hiciera tiempo atrás en centros industriales y comerciales como eran Mérida y Mértola o en centros urbanos del relieve de Córdoba, Sevilla, Toledo o Zaragoza ${ }^{31}$. La emigración de población del sur hacia territorios septentrionales contribuyó a enriquecer aún más este intercambio existente desde época visigoda ${ }^{32}$.

\section{LA TRANSICIÓN EN LOS CENTROS MONÁSTICOS}

La llegada de la escritura carolina al antiguo reino de León tiene lugar dos siglos después que en Cataluña, en cuyo contexto cultural el alfabeto carolino se había establecido ya en el siglo IX. En efecto, el tipo de escritura de los documentos de finales de siglo es una escritura mixta visigótico-carolina caligráfica ${ }^{33}$. En el siglo $X$ la visigótica quedará restringida al ámbito rural mientras que, en los centros monásticos y catedralicios, los códices y documentos se ejecutan en minúscula carolina ${ }^{34}$.

\footnotetext{
${ }^{27}$ Sobre estos talleres y sus técnicas y actividad véase De Santiago 2005, 2015.

${ }^{28}$ Adoptamos el término "scriptoria epigraphica" que definiera Mallon (1952) como los talleres donde artesanos y especialistas grababan las inscripciones en sus diferentes formas y contenidos.

${ }^{29}$ Aunque son escasos los estudios centrados en las transferencias de estos soportes, como estudios referenciales véase Martín Postigo 1972; García Lobo 1979; Caramello 2012; Rodríguez Suárez 2015; Martín López 2017.

${ }^{30}$ Así lo señalan Herrero de la Fuente y Fernández Flórez (2012, p. 77) al estudiar inscripciones como la de Mijangos, la de la iglesia de San Juan de Baños, la roboratio de la cruz de Alfonso III, o las consagraciones de Tábara, Castañeda, Escalada y Montes, las cuales muestran que debía haber algún tipo de vinculación.

${ }^{31}$ Santiago 2015.

${ }^{32}$ Parece evidenciarse este hecho en los centros monásticos que resurgen con la emigración de monjes del sur ( $c f$. García Lobo 2010).

${ }^{33}$ Alturo 1991, p. 36

${ }^{34}$ Alturo 1991, p. 38
} 
En el territorio occidental los factores políticos y culturales no fueron propicios para la adopción de la carolina hasta finales del siglo XI. La escritura había alcanzado en todas sus vertientes un nivel de ejecución alto que no precisaba, como sucediera en otras regiones europeas, de una renovación gráfica $^{35}$. La comunicación social estaba asegurada mediante una visigótica redonda, bien trazada y de lectura asequible para los asuntos jurídicos, intelectuales o publicitarios. No obstante, la política de la dinastía navarra en tiempos de Fernando I y Alfonso VI abre una nueva etapa económica, cultural y religiosa en el reino. El paulatino asentamiento de monjes cluniacenses en el territorio ${ }^{36}$, así como la política exterior abierta al mundo borgoñón, propician un cambio en todos los órdenes y especialmente en la escritura ${ }^{37}$. Así mismo, la reforma y unificación de la liturgia implicó la importación de códices ultra pirenaicos. En este sentido, los concilios de Burgos (1080) y León (1090) son simplemente hitos de partida. Estos concilios hacen referencia al cambio de escritura como un valor relativo, destinado únicamente a los textos de carácter litúrgico pero no a los documentos ${ }^{38}$.

Los monasterios hispanos deben adaptarse a la nueva escritura. Acostumbrados a la visigótica, ésta no puede ser abandonada de golpe toda vez que la renovación libraria llevaría tiempo, pero, además, los documentos, como medio de relaciones económicas de la sociedad, deberían seguir siendo escritos en una escritura conocida y legible por el común. Entre los años 1029 y 1061 se observa en los scriptoria monásticos una tímida presencia de elementos abreviativos carolinos en la documentación ${ }^{39}$ seguida de un periodo de mayor intensidad, todo ello fruto de la presencia y copia de los textos litúrgicos carolinos. Los primeros documentos en carolina, de finales del XI, mantienen aún reminiscencias visigóticas lógicas en unos amanuenses que manejan ambas grafías.

De forma pragmática, la cancillería regia mantiene la escritura visigótica como usual en la expedición de documentos hasta el año 1123, en la última etapa del reinado de Urraca. Así, por ejemplo, en la permuta que hiciera

\footnotetext{
${ }^{35}$ Tan solo en el antiguo reino de Galicia parece que se constata un mayor uso de la escritura cursiva frente a la variante redonda ( $c f$. Castro 2012, pp. 105-114).

${ }^{36}$ Alfonso VI mantiene la alianza con Cluny para mantener un equilibrio entre sus propias ambiciones políticas y las exigencias del Papado ( $c f$. Bishko 1968; Reglero 2008,p. 169; Castro 2016).

${ }^{37}$ Del Camino 2008, pp. 124-125.

${ }^{38}$ Del Camino 2008, p. 127. Durante el reinado de Fernando I (1037-1065) se introducen importantes novedades en la producción libraria. Cierto que dichas innovaciones afectan, primeramente, a los elementos decorativos y las miniaturas. Así, el Libro de Horas de Fernando y Sancha de 1055 muestra, según Moralejo, las primicias de la ilustración románica ( $c f$. Díaz y Díaz, Moralejo 1995, p. 55).

${ }^{39}$ Fernández Flórez 2016, p. 42. Véase el artículo de F. Molina en este monográfico.
} 
la reina con Gómez Iohannis, el documento, suscrito por el notario Andreas, se ejecuta en una escritura visigótica redonda, aunque ya con influencias carolinas ${ }^{40}$. El siguiente documento original que se conserva data del 1 de febrero de 1124 y se trata de una donación de la reina al obispo de Sigüenza, don Bernardo, escrita ya en carolina trazada con una pluma cortada al estilo gótico, suscrita por el notario Pedro Vicéntez ${ }^{41}$. Vemos pues cómo el documento muestra un evidente sentido práctico. La necesidad de hacerse entender y comunicar a la población sobre los asuntos de régimen fiscal y político es la prioridad. El mensaje debe ser leído y comprendido por una ciudadanía poco familiarizada con la escritura y mucho menos con las novedades gráficas que iría asimilando lentamente. A diferencia del ámbito librario litúrgico al que "se obliga" a cambiar de escritura el resto -documentos e inscripciones- seguirán utilizando la escritura visigótica durante un tiempo dilatado. En efecto, la documentación privada mantiene la visigótica dado que se trata de usuarios poco familiarizados con los textos y que podrían desconfiar de una escritura que no dominan ${ }^{42}$.

\section{LA TRANSICIÓN GRÁFICA EN LAS INSCRIPCIONES}

¿Cómo afecta el cambio a las inscripciones? ¿Cómo actúa un medio de comunicación con una proyección social más amplia que los documentos y los libros ${ }^{43}$ donde se publicitan hechos de carácter jurídico e ideas doctrinales o intelectuales en ámbitos abiertos a un lector universal ${ }^{44}$ ? De forma general, se puede afirmar que el proceso de transición de la visigótica a la carolina en las inscripciones es el mismo que en la escritura ordinaria. Quizás podríamos precisar que más retardatario ya que la escritura epigráfica es conservadora por naturaleza y tiende a ir a la zaga respecto a los cambios y novedades que se observan en los libros y en los documentos ${ }^{45}$.

\footnotetext{
${ }^{40}$ Ruiz Albi 2003, n. ${ }^{\circ} 133$.

${ }^{41}$ Ruiz Albi 2003, n. ${ }^{\circ} 138$.

${ }^{42}$ Sobre pervivencia de la escritura visigótica en los territorios occidentales, véase Ostolaza 1990; Ruiz Asencio 2008; Márquez 2007; Calleja 2008. Véase también el capítulo de A. Castro en este volumen.

${ }^{43}$ No hay que olvidar el carácter de publicidad de las inscripciones y la amplia acogida social de este medio escrito entre todas las clases sociales. De ahí la rica y amplia variedad formal de los epígrafes altomedievales. El acto epigráfico era necesario para todas las clases sociales, privilegiadas o no privilegiadas. Velázquez 2014; Martín López 2018.

${ }^{44}$ Sobre las condiciones del lector y la lectura de estos textos hace una reflexión válida para nuestros siglos Debiais 2009.

${ }^{45}$ Hemos podido constatar este carácter retardatario en épocas posteriores en un estudio comparativo (Martín López 2017).
} 
Hay que admitir la convivencia entre los dos sistemas gráficos, visigótico y carolino, a lo largo de todo el siglo XII, aunque no de forma homogénea en todo el territorio occidental. La adopción de la nueva grafía se hizo de forma gradual abarcando la transición entre los últimos años del siglo XI, donde se pueden observar ciertas contaminaciones carolinas en el sistema y signos de abreviación, a una segunda fase de presencia del alfabeto carolino junto a grafías visigóticas y una tercera fase de claro predominio carolino con reminiscencias visigóticas en algunas letras. Podríamos añadir una cuarta fase, localizada en Galicia a principios del siglo XIII donde hallamos los tres alfabetos -visigótico, carolino y gótico- en un mismo soporte ${ }^{46}$.

\subsection{Burgos}

La provincia de Burgos, su correspondiente volumen del corpus recientemente publicado, es un claro ejemplo de lo que puede suceder en otras zonas castellanas donde los estudios epigráficos no están tan avanzados. García Morilla admite la convivencia de los dos sistemas gráficos durante el siglo XII. De las 17 inscripciones que él denomina de transición, 10 están realizadas en una visigótica pura, 3 presentan un alfabeto mixto y otras 3 están escritas en carolina con reminiscencias visigóticas ${ }^{47}$.

La visigótica pura la hallamos en inscripciones de ámbito monástico y eclesiástico, pero también en talleres de escultura y, como no, en talleres ocasionales. Su cronología se dilata hasta mediados del siglo como vemos a continuación. La primera de la serie de visigóticas del XII es el epitafio sepulcral de una religiosa de nombre Godo, enterrada en 1105 en el monasterio de San Pedro de Arlanza, hoy en el museo de Burgos ${ }^{48}$. Fuera del ámbito monástico, el maestro Pedro, ejecutor de la pila bautismal de Santa Eulalia de Mazariegos, utiliza la escritura visigótica para la suscripción de su obra, datada entre 1102 y 1111. En un sillar reutilizado y recortado aún se conserva lo que fue la lápida de consagración de la iglesia de San Miguel Arcángel de Rosales, del año 1122, y donde podemos apreciar una visigótica muy evolucionada que presenta algunos elementos ya carolinos ${ }^{49}$. De discutida datación, quizá de 1145, es la consagración de la iglesia de Santa Eulalia en Santa Olalla. La inscripción está ejecutada íntegramente en visigótica sin atisbo alguno de caro-

\footnotetext{
${ }^{46}$ Fernández García 2003, p. 201.

${ }^{47}$ García Morilla 2018, p. 277

${ }^{48}$ García Morilla 2016, pp. 110-111. Sobre la identidad de este personaje y su dificultad véase García Morilla 2018, p. 285.

${ }^{49}$ García Morilla 2016, p. 113.
} 
lina ${ }^{50}$. De 1132 es el epitafio necrológico de cierto personaje desconocido, de conservación fragmentaria en el monasterio de Santa María de Retortillo ${ }^{51}$. La iglesia de Hormicedo, dedicada a los santos mártires San Quirico y Santa Julita, conserva un epitafio de 1131 de cierto Jimeno ${ }^{52}$. La última inscripción escrita íntegramente en visigótica hace mención a una plantación de huerto en la localidad de Crespos en 1147. Esta inscripción ha sido tildada de tosca por su mala separación de palabras y una "mise en page" poco cuidada, pero los trazos gráficos mantienen un surco firme y las letras presentan un módulo regular en todo el conjunto. El módulo es doble de alto que ancho y conserva todos los elementos característicos; $A$ sin travesaño, $M$ de trazos convergentes, $N$ con trazo intermedio casi horizontal, etc., solo la $U$ en forma de $V$ no es la letra típica del alfabeto visigótico ${ }^{53}$.

En cuanto a las inscripciones con alfabetos mixtos se conservan únicamente tres: la consagración de la iglesia de San Esteban y Santa Coloma de 1114 y dos epitafios necrológicos de 1143 y 1193, ambos localizados en Villamayor de los Montes. Los rogatarios parecen coincidir en las preferencias de letras visigóticas como la $A$ sin travesaño, $E$ rectangular, $O$ romboidal, $M$ de trazos convergentes y $T$ de bucle, mientras que el resto de los elementos gráficos son carolinos. No es de extrañar esta preferencia dado que son las letras más típicas del alfabeto visigótico y, por ende, las más longevas en la memoria gráfica de la cultura popular ${ }^{54}$. Esta preferencia parece intencionada por parte del lapicida tal y como se aprecia en algunas letras, la $O$, la $T$, que presentan un trazado artificial. El resto de las letras son carolinas, con módulo cuadrado y predominio de los trazos curvos en la ejecución de ciertas letras como la $E$ o la $R$ que curva ya su tercer trazo. Todo ello confiere a la pieza un aspecto singular y característico.

Como decimos, las letras señaladas como típicas visigóticas van a tener una larga $v_{i d a}{ }^{55}$. Marcadas en la retina de los lapicidas están presentes en conjuntos epigráficos carolinos. En concreto son tres los casos donde aparecen estas reminiscencias visigóticas. Ciertamente son inscripciones ligadas a talleres ocasionales cuya finalidad es solventar una necesidad publicitaria

\footnotetext{
${ }^{50}$ García Morilla 2016, pp. 113-114.

${ }^{51}$ García Morilla 2016, p. 114.

${ }^{52}$ García Morilla 2016, p. 116.

${ }^{53}$ García Morilla 2018, p. 276.

${ }^{54}$ Hoy en día la $A$ sin travesaño ha tenido una notable aceptación en el diseño gráfico.

${ }^{55}$ Este tipo de escritura encuentra algunos antecedentes gráficos en el hábito epigráfico de época visigoda. En especial la combinación de mayúsculas unciales y minúsculas agrandadas, así como el uso de algunas letras como la $O$ romboidal o la $T$ de bucle a la izquierda. Sin embargo, a partir de los inicios de la Reconquista la escritura visigótica alcanzará formas propias que la irán definiendo a lo largo de las cuatro centurias siguientes (cf. De Santiago 2009, p. 300).
} 
concreta ${ }^{56}$. Sus actores estaban en contacto con la escritura carolina, la conocían y manejaban, pero no habían olvidado su escritura propia quizá por ser la primigenia que aprendieron $\mathrm{y}$, por tanto, la más familiar. No hay que olvidar que en todos estos casos el autor del texto y el autor material buscan una misma cosa, esto es hacer llegar el mensaje al público de manera eficaz ${ }^{57}$.

\subsection{Zamora}

El corpus de la provincia de Zamora ${ }^{58}$ muestra unos parámetros distintos donde la visigótica entra en desuso a principios del XII. En 1082 tenemos el primer testimonio de elementos gráficos carolinos en el monumentum aedificationis de la iglesia parroquial de Pobladura de Aliste. Se trata de una lápida de mármol donde el alfabeto visigótico se halla salpicado de elementos carolinos. Su confección es bastante tosca, producto de un taller ocasional, al que contribuye el módulo irregular de las letras ${ }^{59}$. La primera inscripción conservada escrita completamente en carolina data de 1137, una fecha tardía que solo se explicaría por el expolio del patrimonio epigráfico de esta provincia. Se trata de la consagración de la iglesia de Santa María de Tábara por el obispo de Astorga ${ }^{60}$. Este monasterio mantiene una actividad escrituraria a lo largo de toda la Alta Edad Media y es poseedor de algunos de los epígrafes más notables en cuanto a calidad gráfica se refiere. Sin duda, no es el primer caso de escritura carolina toda vez que hallamos adopción de elementos gráficos carolinos en varias inscripciones de finales del siglo XI, lo que nos llevaría en buena lógica a pensar que la carolina se implanta con fuerza en el territorio mucho antes. Desde luego, el ambiente monástico era propicio, con centros de actividad cultural reconocida como el ya mencionado Tábara o el monasterio de Castañeda.

Algunos de los casos resultan curiosos, como son las inscripciones que se conservan en la iglesia de San Cipriano en la capital zamorana. A diferencia de las anteriores estas piezas están vinculadas a talleres artesanales. En el muro exterior del templo hallamos un bajorrelieve datado en 1094 que representa una escena en la que están tres personajes; de rodillas uno y dos en cuclillas en actitud de trabajar la piedra. Se trata de una representación

\footnotetext{
${ }^{56}$ Martín López 2007, pp. 203-227; García Morilla 2014, pp. 145-154.

${ }^{57}$ García Lobo, Martín López 1995, p. 40; García Morilla 2018, pp. 271-302.

${ }^{58}$ Gutiérrez 1995.

${ }^{59}$ Gutiérrez 1995, vol. II, n. ${ }^{\circ} 8$.

${ }^{60}$ Gutiérrez 1995, vol. II, n. ${ }^{\circ} 15$.
} 
espontánea de los propios canteros que se retratan ${ }^{61}$. Iluminando la escena se dispone una explanatio "Manomentum" que hace alusión al sepulcro que estarían confeccionando. No es el único bajorrelieve de este edificio ya que un herrero de nombre Vermudo deja constancia de su actividad profesional con el mensaje Vermudo ferario, qui fecit memoria de sua fravica ${ }^{62}$. Son los propios artesanos los que elaboran los epígrafes en escritura visigótica con la $A$ sin travesaño y la $T$ de bucle típicas, pero mezclan estas grafías con otras nuevas carolinas que ya conocen pero que aún no dominan. Son textos que ellos mismos elaboran de forma espontánea, de ahí su lenguaje, que resultan de gran interés ya que nos informan que en este momento hay un contacto con la escritura carolina por parte no solo de los monjes, que sería lógico, sino por parte de estos trabajadores que saben leer y escribir. Todo parece denotar que la escritura carolina se introduce pronto en la epigrafía a pesar de los escasos testimonios conservados.

\subsection{Cantabria}

Nuestro recorrido continúa con Cantabria, territorio que conserva un alto número de inscripciones visigóticas con un total de $68^{63}$ lo que denota la elevada producción publicitaria entre los siglos VIII al XI; desde el epitaphium necrologicum de Riloa en la cubierta de sarcófago de Bárcena de Ebro (año 882) hasta la consecratio de San Lorenzo de Pujayo de 1132. Esto no impide que la escritura carolina se documente tempranamente en una inscripción de la iglesia de Santa María de Bareyo datada en 1084. Se trata del epitafio necrológico de un tal Munio ${ }^{64}$. Con todo, la escritura carolina no se generaliza hasta bien entrado el siglo XII y siempre conviviendo con la escritura visigótica ${ }^{65}$.

\footnotetext{
${ }^{61}$ Gutiérrez 1995, vol. II, n. ${ }^{\circ} 14$.

${ }^{62}$ Gutiérrez 1995, vol. II, n. ${ }^{\circ} 13$. Estas suscriptiones serán frecuentes en el siglo XII por el desarrollo de los talleres profesionales y artesanales relacionados con la construcción de monasterios (García Lobo, Martín López 1996b); son numerosos los ejemplos. El repertorio o catálogo más completo, primero de Italia y luego de Europa, es de Dietl 2008.

${ }^{63}$ La colección epigráfica está formada cronológicamente por: 26 (siglo VIII), 17 (siglo IX), 9 (siglo X), 16 (siglo XI), 29 (siglo XII), 24 (siglo XIII), 17 (siglo XIV), 28 (siglo XV), 4 (siglos XV-XVI). Peña Fernández, 2019.

${ }^{64}$ Peña Fernández 2009, p. 120; 2019, n. ${ }^{\circ}$ 59. En realidad, se trata de la contaminación entre formas gráficas de la visigótica y la carolina, aunque con predominio de la primera.

${ }^{65}$ La cronología de la carolina en Cantabria llegará hasta los inicios de la segunda mitad del siglo XIII, cuya epigrafía fechada más avanzada en este tipo de escritura la encontramos en la consecratio de Barruelo de los Carabeos fechada en 1264 ( $c f$. Peña Fernández 2019, n. ${ }^{\circ}$ 111). En esta inscripción y en otras que, aunque no presentan data explícita se sitúan cronológicamente atendiendo a criterios paleográficos a lo largo de la primera mitad del siglo XIII, son
} 
Los primeros indicios de escritura carolina en epígrafes visigóticos se documentan entre 1081 y 1085 en tres inscripciones: el epitaphium sepulcrale de cierto Pedro en la puerta de entrada a la colegiata de Santillana del Mar (1081), el ya citado epitaphium necrologicum de Munio en la iglesia de Santa María de Bareyo (1084) y la consecratio de San Miguel de Pesquera (1085) localizada en los sillares del muro sur ${ }^{66}$. Estos indicios se concretan en el uso de algunas letras aisladas del alfabeto carolino posiblemente influenciados por la escritura de los textos litúrgicos que comienzan a estar en carolina, lo que nos lleva a reflexionar sobre la adscripción de estas inscripciones a un determinado taller. Hablar de una oficina lapidaria no alude a una ubicación física concreta sino a una producción de unas inscripciones que presentan características similares y un marco geográfico cercano que permita su adscripción a un taller ${ }^{67}$. Alberto Peña sigue estos parámetros y determina los principales talleres epigráficos en los monasterios de Santa Juliana de Santillana del Mar, Santa María de Piasca, San Martín de Elines, San Pedro de Cervatos, Santa Cruz de Castañeda y la catedral de Santander. Todos estos centros tienen como denominador común su proyección cultural sobre su jurisdicción territorial monástica. Así mismo, los testimonios epigráficos conservados en algunos templos -afirma Peña- hacen pensar en la posible existencia de scriptoria propios en sus dependencias, como es el caso de San Andrés de Argomilla de Cayón $^{68}$. En el periodo de ejecución de estas piezas citadas el centro más potente de producción es el monasterio de Santa Juliana de Santillana por su alta producción escrita conservada de libros litúrgicos y documentos. Tenemos que pensar que su rico lapidario es fruto de un taller vinculado al scriptorium, como sucede en otros monasterios, con un mismo personal para la ejecución de todas o parte de las tareas que afectaban a la escrituración ${ }^{69}$. De ahí posiblemente la temprana adopción de elementos carolinos que localizamos, como hemos dicho, en el epitafio de Pedro en 1081.

La convivencia entre ambas grafías, con todo, se mantiene hasta 1132 , donde en algunas inscripciones carolinas encontramos reminiscencias del alfabeto visigótico indelebles en la memoria de los lapicidas. Es el caso de epitaphium sepulcrale de San Martín de Elines (1119), al monumentum aedificationis de San Pedro de Cervatos (1129) y a la consecratio de San Lorenzo de

\footnotetext{
ya perceptibles las influencias de la escritura gótica que comenzará a asentarse a partir de esta centuria para generalizarse en la siguiente.

${ }^{66}$ Peña Fernández 2019, n. ${ }^{\circ}$ 58, 59, 60 respectivamente.

${ }^{67}$ Peña Fernández 2019, n. ${ }^{\circ} 1-20$.

${ }^{68}$ Peña Fernández 2019. A su vez cita a Bohigas Roldán, et al. 1988.

${ }^{69}$ Blasco Martínez 1992-1993, pp. 13-16.
} 
Pujayo $(1132)^{70}$. La conservación de la escritura visigótica se debe relacionar con el hecho de que la cultura escrita estuvo circunscrita a los monasterios del territorio, muchos de ellos familiares ${ }^{71}$. El monasterio benedictino de San Martín de Elines, en la comarca de Campoo, tiene sus orígenes en el siglo X y en el XII es uno de los más influyentes en el valle ${ }^{72}$. Su edificio románico es un claro testimonio de su esplendor pasado con la presencia de un taller románico de nivel ${ }^{73}$. Con la desaparición de la comunidad su documentación se dispersa y desaparece; de su scriptorium tan solo resta su epigrafía y una parte de su documentación en el archivo catedralicio de Burgos. El scriptorium epigráfico tiene su máxima actividad durante los siglos XII y XIII, periodo de construcción de la magnífica iglesia, conservándose ocho sepulcros de este periodo. El epitafio sepulcral muestra un lenguaje retórico que se mantiene como nota característica en la producción posterior. Ciertamente, nos habla de cierta persona santa pero no concreta su identidad. La escritura es parecida a la utilizada en otra cubierta de sarcófago del lapidario monástico, lo que denota la consolidada actividad del taller epigráfico. Llama la atención, desde un punto de vista paleográfico, la presencia de la vocal $U$ en forma de $A$ invertida con doble travesaño horizontal, el uso recurrente de nexos o la combinación de diferentes signos de abreviación como la raya horizontal o el medio yugo. El trazado de las letras es elegante, con formas decoradas. Todo ello no se corresponde con la errónea distribución del texto por parte del ordinator, teniendo que separar excesivamente las letras y los numerales del año al final de la última línea, ofreciendo un acabado imperfecto ${ }^{74}$.

Con los años, la perfección técnica es alcanzada de manera que podemos apreciarla en el sepulcro del abad Pedro (CIHM, 5, n. ${ }^{\circ}$ 93), claro testimonio del esplendor de este taller donde la rica decoración se funde con el texto en una armoniosa conjunción. El taller monástico continúa con la creación de sepulcros para sus abades, actividad epigráfica que pervive a lo largo del siglo XIII. Los textos funerarios, por su parte, muestran un formulario tradicional donde no faltan las alusiones al difunto y la petitio de oraciones pro anima. La presencia del apreciativo orate pro illo, así como los sincronismos religiosos, denotan la acción del personal del scriptorium monástico. En él se confecciona la minuta del epitafio con el formulario seleccionado y el diseño

\footnotetext{
${ }^{70}$ Peña Fernández 2019, n. ${ }^{\circ}$ 69, 72,73 respectivamente.

${ }^{71}$ Peña Fernández 2019, n. ${ }^{\circ} 1-20$.

${ }^{72}$ Fue elevada a colegiata por Paulo III a petición de Juan Fernández Manrique, tercer marqués de Aguilar de Campoo. Cf. García Guinea, et al. 2007 (Enciclopedia del Románico III), 1426.

${ }^{73}$ Gutiérrez López 2000, p. 56.

${ }^{74}$ Peña Fernández 2002, p. 23; 2019, n. ${ }^{\circ} 69$.
} 
de letras ${ }^{75}$. Un magister debía estar al frente de la actividad epigráfica, controlando las tareas escriptorias y confeccionando los textos laudatorios de los epitafios.

El monasterio de San Pedro de Cervatos, al sur de Cantabria en el territorio de Campoo de Enmedio, levantado en plena repoblación intramontana en una vía-nudo de conexión meseta-costa, era importante tanto para la defensa como para la expansión. Las fuentes documentales se completan en este periodo inicial con los testimonios epigráficos al convertirse en centro de enterramiento de la nobleza ${ }^{76}$. El primero (1129) nos habla de su construcción, mientras que el segundo (1199) recoge la dedicación del templo ${ }^{77}$ y también nos hablan del paso del esplendor a la decadencia económica y cultural del centro en pocos años ${ }^{78}$. La primera inscripción (1129) confeccionada en un alfabeto mixto, presenta unas trazas simétricas, un correcto espejo epigráfico, mientras que en la segunda (1199) no existe preparación alguna del soporte y se agolpan las palabras, con mala separación, con letras de desajustado módulo que nos informan del inicio de una nueva etapa nada propicia para la comunidad ni para su scriptorium.

\subsection{Asturias}

Asturias conserva la epigrafía medieval más completa y notable. Las piezas asturianas están confeccionadas en talleres que se organizan tempra-

\footnotetext{
${ }^{75}$ Sobre este aspecto, aunque no se conservan las minutas por estar trazadas en materia desechable bien sea pergamino o papel, sí nos quedan reflejos de su existencia en las puestas en limpio en la piedra. Me refiero a los errores de rogatario cuando éste no identifica los signos gráficos o no los interpreta bien. Véase García Lobo, Martín López 1995, pp. 151-161.

${ }^{76} \mathrm{El}$ conde castellano Sancho García (995-1017) funda el panteón condal. Assas da noticia del enterramiento de Alfonso, hijo del rey leonés Bermudo III, quien estaba casado con Jimena, hija del conde Sancho García. El cartulario de Cervatos, del que solo tenemos noticia por una copia de su contenido del siglo XVIII, recoge las noticias de estos enterramientos. $C f$. García Guinea, et al. 2007 (Enciclopedia del Románico III), 1152-1153.

${ }^{77}$ El siglo XIII inicia la decadencia lenta del monasterio. A pesar de los esfuerzos regios por su recuperación en el siglo XV, San Pedro no volverá a tener el relieve anterior dejando de ser monasterio para ser canónica regular en el siglo XIV ( $c f$. González de Fauve 1992, vol. I, p. 144).

${ }^{78}$ Este hecho es constatable en otros establecimientos cuando caen en crisis. Por ejemplo, San Miguel de Escalada, que contaba con un magnífico scriptorium en el siglo X; el más importante del reino, productor y exportador de códices como los conocidos beatos bajo la dirección y pluma de Magius, creador del conocido Antifonario de la Catedral de León. Cuando el monasterio atraviesa una crisis interna en el siglo XI su scriptorium ralentiza su producción. Las inscripciones son buen reflejo. De las magníficas aras de altar (913) de elegante y cuidada ejecución, se pasa a inscripciones como la que jalona el dintel de la puerta en una visigótica torpe sin impaginatio (véase Cavero, García Lobo 2013). Compartimos con estos editores, concretamente García Lobo, la pertenencia de Magius al scriptorium de Escalada, donde realiza buena parte de su obra, aunque trabajara posteriormente en Tábara.
} 
namente y producen inscripciones elegantes con textos ricos y cuidados en su forma literaria, donde se destacan las cualidades humanas frente a la utilización general de tópicos formulísticos que hacen referencia a la moral. De esta manera, los personajes en ellas perpetuados se hacen más cercanos para nosotros a pesar de los siglos de distancia ${ }^{79}$.

En efecto, la producción epigráfica ha sido intensa en la Alta Edad Media en todo el territorio asturiano. La actividad monástica y la utilización de la epigrafía por parte de la monarquía como medio de propaganda y publicidad hacen que el consumo de inscripciones sea muy alto. Así lo demuestran las estadísticas, con un total de 96 inscripciones conservadas datadas entre los siglos IX al XI. Los talleres recurren a una escritura visigótica caracterizada por un módulo regular, surco firme, pocas abreviaturas, y una impaginatio correcta hasta la primera década del siglo XII. Estas condiciones las hallamos en el epitafio del abad Iustus (1107) cuyo texto nos recuerda que él restauró con su propio trabajo la iglesia ${ }^{80}$, o en la dedicatio de los altares de la iglesia de Santo Adriano en Tuñón (1108) ${ }^{81}$. Este monasterio, fundado por Alfonso II (891), inmortaliza la restauración con una larga e interesante inscripción de 0,75 x 0,49 m. Presenta una orla en forma de cordón como las que podemos ver en otras inscripciones, por ejemplo, Cartabia. El largo texto se distribuye armoniosamente a pesar de un apretado reglado sin separación de palabras de manera que el lapicida tuvo que recurrir finalmente al uso de abreviaturas. Su escritura presenta peculiaridades propias como el predominio de letras de trazos rectos. Debemos destacar la ejecución de la $G$, la $O$ de cuerpo regular, y la $M$ de trazos curvos que se combina con la capital.

La escritura carolina se halla presente en las primeras décadas del siglo XII, donde el primer testimonio que se conserva es el epitafio del abad Rodrigo (1114) en el monasterio de Cangas de Onís ${ }^{82}$. La pieza es una teja instalada en el muro toral con una escritura carolina que mezcla caracteres mayúsculos con letras minúsculas $(a, b)$. En fin, debemos esperar a 1121 para encontrarnos con una inscripción en caracteres íntegramente mayúsculos como es la consagración de la iglesia de Santa Eulalia de Dóriga ${ }^{83}$.

\footnotetext{
${ }^{79}$ Sin duda el mensaje consigue calar más hondo en el lector, sensible a este recurso. Sobre este tema nos habla ampliamente García Lobo 2011.

${ }^{80}$ Diego Santos 1995, p. 145.

${ }^{81}$ Diego Santos 1995, p. 179.

${ }^{82}$ Diego Santos 1995, p. 228.

${ }^{83}$ Diego Santos 1995, p. 174.
} 


\subsection{Orense}

Nos acercamos ya en este recorrido a los territorios más occidentales. No contamos con una estadística completa de las inscripciones gallegas. Únicamente se han recopilado las inscripciones de la provincia de Orense que servirán de pauta para nuestro estudio. Se conservan un total de 147 inscripciones medievales ${ }^{84}$. Quizá no llame la atención cuantitativamente, pero resultan de un interés extraordinario por su diversidad gráfica y por su tipología ${ }^{85}$. La escritura visigótica se extiende desde el siglo IX hasta el siglo XIII en 22 inscripciones que han llegado a nosotros en muy diferente grado de conservación. En cuanto a los talleres de producción destaca el del monasterio de Santa Cristina de Ribas de $\mathrm{Sil}^{86}$ mientras que el resto se hallan dispersas por el territorio orensano.

La transición de la visigótica a la carolina se sitúa en un marco cronológico en que en Galicia confluyen tres tipos de escritura, la visigótica, la carolina y la gótica. Las condiciones geográficas e históricas implican una lentitud inusitada en la desaparición de la antigua escritura peninsular. A su vez, la escritura carolina se conoce y se emplea en las inscripciones gallegas en los mismos tiempos en que las hallamos en otras zonas del reino. No olvidemos que este territorio estaba abierto a las novedades a través del Camino de Santiago. Por medio de la vía jacobea llegan maestros escultores hasta Santiago, pasando por Lugo y dejando en sus sedes catedralicias muestras de la carolina más elegante y evolucionada. No obstante, Orense presenta unas condiciones bien distintas. La primera inscripción conservada en escritura carolina es la datatio del antiguo palacio episcopal del año $1131^{87}$, que comenzó a construirse a partir del auge relevante de la organización urbana de la ciudad de Orense. No es casual que hallemos esta epigrafía en suelo urbano.

El claustro del monasterio de Santa María la Real de Xunqueira de Ambía conserva los restos fragmentarios de lo que en su día debió ser el obituario en piedra de la comunidad, al modo de tantos otros que se crearon a lo largo de los siglos XII y XIII como Roda de Isábena, San Juan de la Peña, Silos, San Isidoro, San Miguel de Escalada o Santa Cristina de Ribas de Sil por citar los más destacados. Pues bien, de ese conjunto casi desaparecido se

${ }^{84}$ Muestran una homogénea distribución cronológica: 18 (ss. IX-X), 36 (ss. XI-XII), 45 (s. XIII), 26 (s. XIV), 18 (s. XV).

${ }^{85}$ Fernández García 2020.

${ }^{86}$ Sobre Santa Cristina, véase Fernández Suárez 1978. Un estudio monográfico detallado de este centro monástico y su taller lapidario en Fernández García 2003.

${ }^{87}$ Esta inscripción vincula la construcción del palacio al obispo Diego III (1100-1132) (cf. Fernández García 2020, n. . 29). 
conserva el epitafio necrológico de un presbítero de nombre Benito (1110) ${ }^{88}$ escrito en un alfabeto mixto.

La convivencia de ambos alfabetos en el territorio se realiza con total normalidad. Así, en 1150 cuando comienzan las obras pictóricas del mapamundi en el monasterio de San Pedro de Rocas, las explanationes que identifican cada imagen se ejecutan en carolina, como no podría ser de otra manera en un taller de profesionales inmersos en el estilo románico. A la par, en 1152 quien determinara la confección del epitafio de María, una devota que elige la iglesia de Santiago en Allariz para su enterramiento, determina que el mensaje se realice en escritura visigótica ${ }^{89}$. Estamos ante dos realidades bien distintas; la primera inmersa en el circuito cultural del momento y la segunda que mantiene su tradición gráfica anterior.

Las razones de selección de una escritura u otra podrían ser puramente sociales. El monasterio propio de Santa María de Amoeiro elige la escritura visigótica para publicitar la consagración de su iglesia. La inscripción situada en el exterior del muro occidental muestra un módulo regular y trazos firmes ${ }^{90}$. La escritura carolina es sobradamente conocida por los monjes de manera que la elección de la escritura visigótica no es casual. En este caso se trata de emular la primigenia consagración del templo acontecida en el año 938 y hoy desaparecida. Podríamos hallar, además, otras motivaciones como el hecho de que la feligresía estuviera más familiarizada con la visigótica. Cualquiera de estas razones habría impulsado la misma elección de alfabeto para el monumentum fundationis de Santa María de Xunqueira de Ambía de $1164^{91}$. Como la anterior, esta inscripción está escrita en un bloque de granito y se halla adosada al muro occidental del templo, aunque según Juan Luis Saco su localización originaria fuera otra, en el tímpano de la portada ${ }^{92}$. Cuando en el siglo XVI la feligresía y el rector de la iglesia deciden hacer una copia epigráfica ésta será imitativa de la original, en escritura visigótica, lo que denota la identificación y raigambre de estos elementos gráficos ${ }^{93}$.

La alternancia entre la visigótica y la carolina sigue siendo una constante en la provincia durante la segunda mitad del siglo XII. En 1170, la inscripción de fundación de Santo Tomé de Serantes se confecciona en

\footnotetext{
${ }^{88}$ Fernández García 2020, n. ${ }^{\circ} 27$.

${ }^{89}$ Fernández García 2020, n. ${ }^{\circ} 31$.

${ }^{90} \mathrm{El}$ texto: "Era ICC pridie kalendas februarii Iohanes presbiter fecit dedicacione ecclesie". Se ha identificado a este personaje con el monje Juan de Amoeiro a través de un pleito de 1174 en el que interviene ( $c f$. Fernández García 2020, n. ${ }^{\circ} 33$ ).

${ }^{91}$ Fernández García 2020, n. ${ }^{\circ} 34$.

${ }^{92}$ Fernández García 2020, n. ${ }^{\circ} 34$.

${ }^{93}$ La imitativa ha sido considerada como la original durante años hasta el descubrimiento de la original por Saco (1990-1991).
} 
escritura carolina ${ }^{94}$, mientras que las que se conservan en Arrabaldo (1174) y San Facundo (1176) ${ }^{95}$ se realizan en visigótica. A finales de siglo, la composición de alfabetos mixtos se hace inevitable y tenemos un testimonio de ello en la confección del epitafio sepulcral del abad Fernando en Santa Cristina de Ribas de Sil. El alfabeto se compone en su mayor parte por letras de tradición capital $(D, E, T)$ que se intercalan con otras visigóticas como la $A$ sin travesaño, la $N$ de trazo central horizontal, $O$ ovalada, o $R$ de tercer trazo recto ${ }^{96}$. En el mismo contexto hallamos el epitafio del abad Domingo con unas características similares. El mal estado de las otras inscripciones restantes no impide que se identifique la pervivencia de elementos visigóticos junto a formas carolinas tan populares como el semicolon (-us), y letras de tradición uncial $(A, B, E)$. La escritura carolina entra en los territorios occidentales con una morfología muy evolucionada, con formas predominantemente unciales, que Koch denomina "escritura románica". Su recorrido temporal en la epigrafía es corto siendo sustituida pronto por la gótica ${ }^{97}$. Su gotización se observa, una vez más, en Ribas de Sil. El epitafio del abad Juan de principios del siglo XIII muestra una amalgama de los tres alfabetos -visigótico, carolino, gótico- dando al epígrafe un carácter único. Todo parece llevar un "tempo" más lento en este territorio y creo que lo encontraremos en otras zonas gallegas sin tener que recurrir al tópico de centros ocasionales o dispersos sino también en monasterios. La última inscripción realizada en visigótica es la datatio de la iglesia parroquial de San Pedro de Mezquita de 1202. Su texto recuerda los infortunios de ese año para la zona: in anno malo era millesima ducentesima quadragesima ${ }^{98}$. Es un texto para ser leído por el común, de manera que resulta más publicitaria la escritura visigótica, conocida y familiar, que la gótica, aún en su primera etapa de instauración. En definitiva, se prioriza la difusión del mensaje y no la actualización o modernización del alfabeto.

\section{CONCLUSIÓN}

Queda mucho trabajo por hacer. Las inscripciones constituyen una fuente de estudio de la escritura que, hasta estos últimos años, salvo excep-

\footnotetext{
${ }^{94}$ Fernández García 2020, n. 37.

${ }^{95}$ Fernández García 2020, n. ${ }^{\circ}$ 38-39.

${ }^{96}$ Fernández García 2003, pp. 192-193.

${ }^{97}$ Sobre la convivencia de las tres grafías véase Koch 2007, p. 147. La escritura carolina se mantiene hasta 1230 (véase Fernández García 2020 , n. ${ }^{\circ} 60-65,68,70,71,75$ ) junto a la gótica (Fernández García 2020, n. . 66, 74). Más detalles al respecto en Fernández García 2003, p. 194.

${ }^{98}$ Fernández García 2020, n. ${ }^{\circ} 67$.
} 
ciones, no se ha tenido en cuenta en los estudios paleográficos. La creación de un Corpus de inscripciones proporciona las herramientas necesarias para trabajar exhaustivamente estas piezas escritas y conocer más de sus centros productores y su relación con los libros y los documentos. Los tres objetos escritos coinciden en fases de conscriptio. Tenemos indicios de la participación de escribas en el proceso de la ordinatio; por poner un ejemplo, lo vemos en el epitafio del abad Esteban de Santiago de Peñalba, así como en la patena hoy en el Louvre.

La selección de inscripciones de transición de este estudio debería ampliarse cuando el corpus de fuentes epigráficas esté más avanzado. Las asimetrías cronológicas en los territorios peninsulares en la adopción de la escritura carolina, cómo se entiende y valora esta escritura y la permanencia en el tejido social de la escritura visigótica resulta, no obstante, ilustrativo. El siglo XII es un tiempo de transición en que la intervención de talleres monásticos dará paso a la secularización de la escritura y al desarrollo de la misma en talleres artesanales. Junto a la plena asimilación de la escritura carolina de unas zonas, hallamos la pervivencia de las formas visigóticas en otras como reflejo de un conservadurismo que, creo, no es exclusivo de la periferia del reino ni del contexto cultural leonés. No existe una franja geográfica o cultural. Los centros de producción ocasionales no son tan elevados como en un principio pareciera. Muchas inscripciones se vinculan a centros de órdenes monásticas de larga tradición escrita como los benedictinos. Las inscripciones se realizarían en los propios monasterios con el personal experto en redactar los textos y aplicar las fórmulas apropiadas, así como las técnicas epigráficas. Los trazos sencillos a cincel, pero firmes y bien perfilados, con una baja utilización de abreviaturas con la inserción de algunas letras, participa en la retórica gráfica heredada de la antigüedad tardía y visigoda que se mantiene como una seña cultural. Todo ello redundará en beneficio de la visualización del mensaje epigráfico. Este formato de formas sobrias es bien acogido por un público más interesado en leer el mensaje que en la estética rebuscada en la que caerá la carolina. El planteamiento de una escritura austera, rectilínea, simétrica, facilita la difusión a un público amplio. Las grafías visigóticas son familiares, llevan siglos utilizándose, de manera que se prioriza la efectividad de difusión del texto a la novedad gráfica. En este sentido, creo que la razón esgrimida durante tiempo de atribuir retraso gráfico a estas zonas no está sustentada. Se conocen las dos grafías, incluso conviven tres grafías en un mismo momento. El alfabeto visigótico se sigue enseñando y se sigue leyendo y vemos que, para algunos casos, es más deseable para escribir y transmitir eficazmente un mensaje. 


\section{FIGURAS}

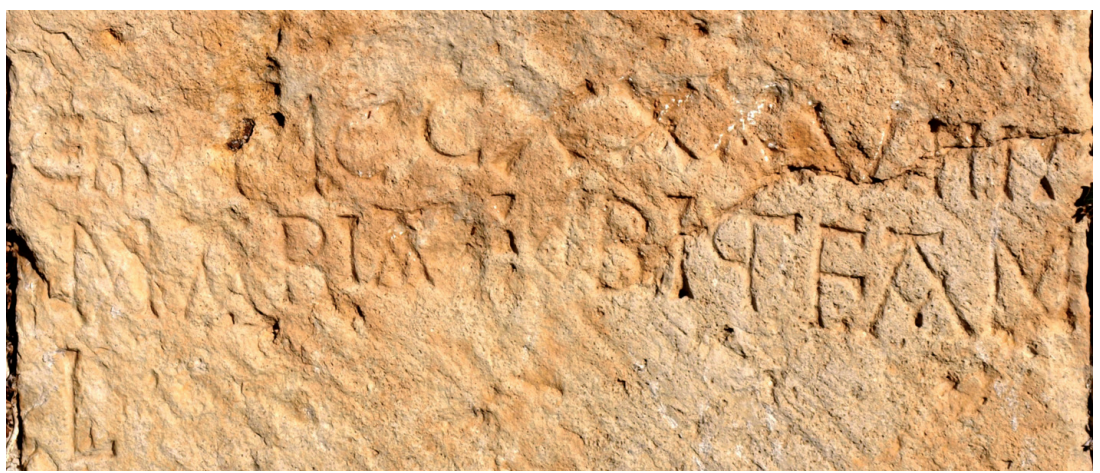

Fig. 1. Epitaphium necrológico. Fotografía: CIHM 1.



Fig. 2. Monumentum plantationis. Fotografía: CIHM 1. 


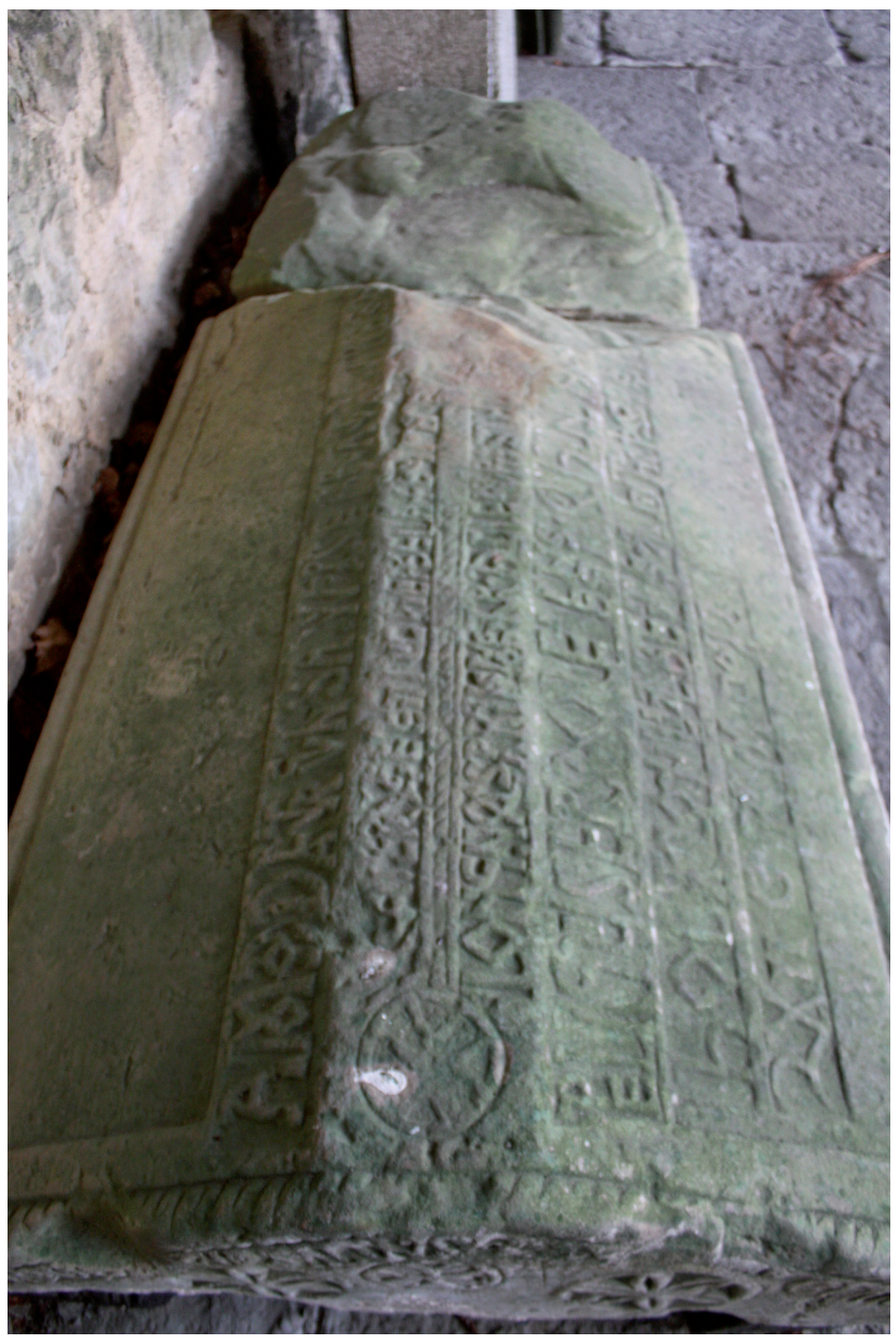

Fig. 3. Epitaphium sepulcral, Santillana del Mar. Fotografía: CIHM 5. 


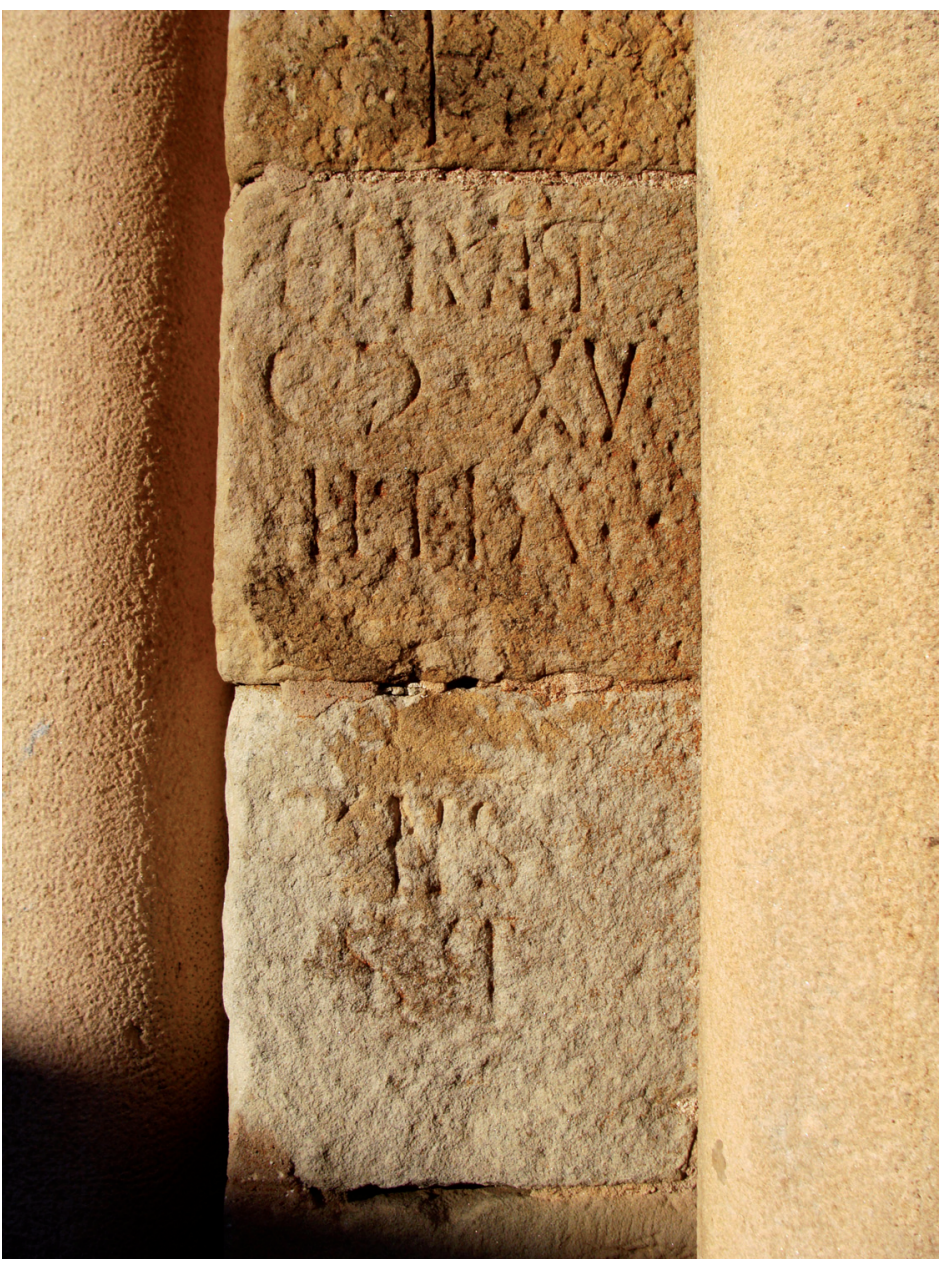

Fig. 4. Monumentum aedificationis de la iglesia de San Pedro de Cervatos. Fotografía: CIHM 5. 


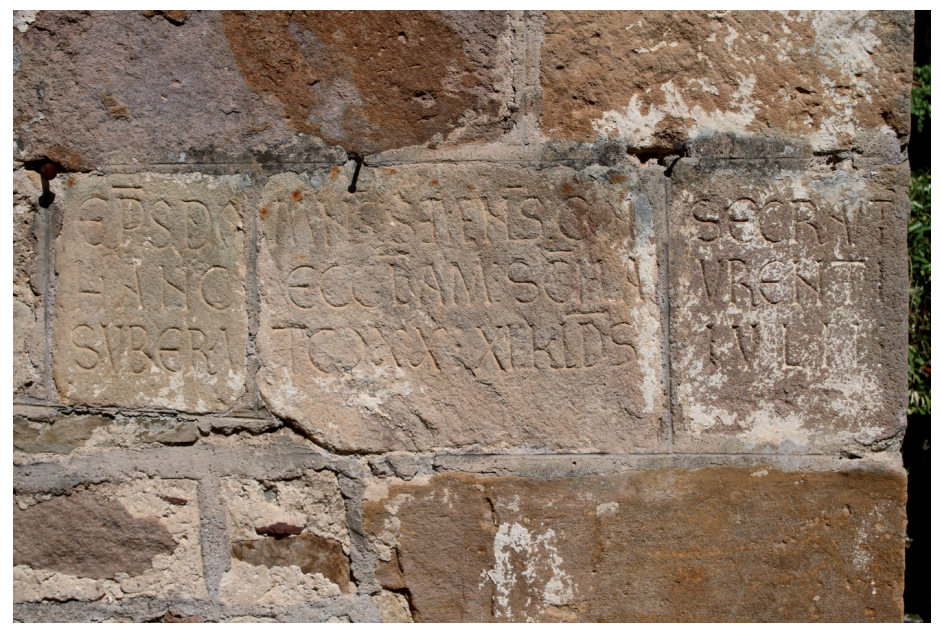

Fig. 5. Notitia de inundación. Fotografía: CIHM 5.
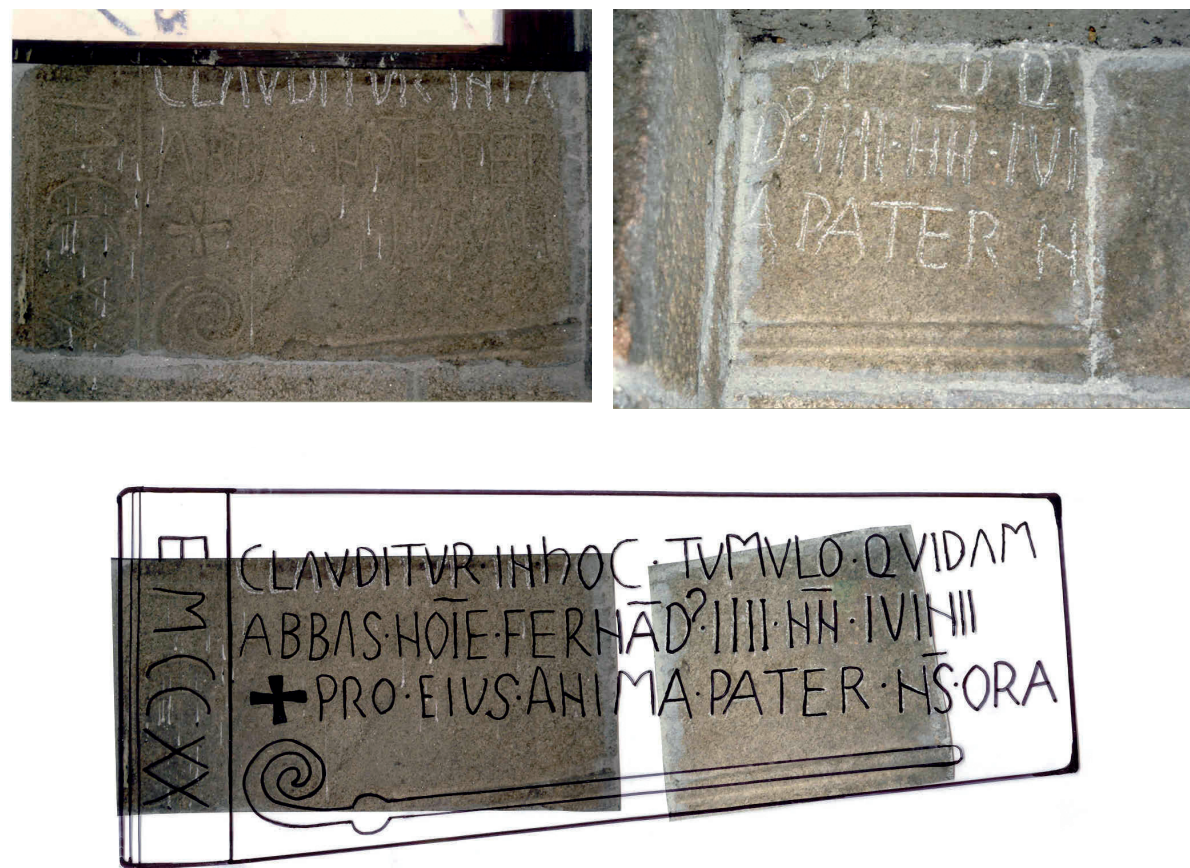

Figs. 6, 7, 8. Epitaphium sepulcral, Santa Cristina de Ribas de Sil. Fotografías: CIHM 7. 


\section{BIBLIOGRAFÍA CITADA}

Alturo Perucho, Jesús (1991), Escritura visigótica y escritura carolina en el contexto cultural de la Cataluña del siglo IX, "Memoria Eclesiae" 2, pp. 33-44.

Alturo Perucho, Jesús; Torra Cortina, Miquel; Castro Correa, Ainoa (eds.) (2012), La escritura visigótica en la Península Ibérica: nuevas aportaciones, Bellaterra, Universitat Autònoma de Barcelona.

Banti, Ottavio (1995), Epigrafie Medioevale o paleografía. Specificità dell'analisi epigraphica, "Scrittura e civiltà" 19, pp. 31-52.

Banti, Ottavio (2000), Dall'epigrafía romanica alla pre-umanistica, "Scrittura e civiltà" 24, pp. 61-101.

Bishko, Charles J. (1968), Fernando I y los orígenes de la alianza castellano leonesa con Cluny, "Cuaderno de Historia de España" 47-48, pp. 31-135.

Blasco Martínez, Rosa (1992-1993), El monasterio como centro emisor y conservador de documentación entre los siglos IX y XII, "Altamira: revista del centro de Estudios Montañeses" 50, pp. 13-26.

Bohigas Roldán, Ramón; Fernández Arce, Isabel; Sarabia Rogina, Pedro; Sobremazas Salcines, Ana (1988), Los sarcófagos medievales de Argomilla de Cayón, "Altamira: Revista del Centro de Estudios Montañeses" 47, pp. 129-160.

Calleja Puerta, Miguel (2008), De la visigótica a la carolina en los documentos del archivo de San Vicente de Oviedo, en Paleografía I: La escritura en España hasta 1250, Burgos, Universidad de Burgos, pp. 191-200.

Caramello, Eva (2012), Paléographie comparée des écritures épigraphiques et manuscrites: une méthodologie en évolution, "Documenta et instrumenta" 10, pp. 131-146.

Castro Correa, Ainoa (2012), La escritura visigótica redonda en Galicia en su periodo primitivo, en La escritura visigótica en la Península Ibérica: nuevas aportaciones, Bellaterra, Universitat Autònoma de Barcelona, pp. 105-114.

Castro Correa, Ainoa (2016), Visigothic script vs. Caroline minuscule: the collision of two cultural worlds in twelfth-century Galicia, "Mediaeval Studies" 78, pp. 203-242.

Cavero Domínguez, Gregoria; García Lobo, Vicente (eds.) (2013), San Miguel de Escalada, León, Instituto de Estudios Medievales.

De Santiago Fernández, Javier (2003), La epigrafía latina medieval en los condados catalanes (815-circ. 1150), Madrid, Castellum.

De Santiago Fernández, Javier (2005), La escritura de las inscripciones cristianas de Mértola, "Documenta e Instrumenta" 3, pp. 187-215. 
De Santiago Fernández, Javier (2009), El hábito epigráfico en la Hispania visigoda, en VIII Jornadas Científicas sobre Documentación de la Hispania altomedieval (ss. VI-X), Madrid, Universidad Complutense de Madrid, pp. 133-170.

De Santiago Fernández, Javier (2012), Publicidad, escritura expuesta e Iglesia en los condados catalanes (ss. IX-XII), "Cuadernos de investigación histórica" 29, pp. 133-158.

De Santiago Fernández, Javier (2015), El hábito epigráfico en la ciudad hispana: de Roma al Renacimiento, en Lugares de escritura: la ciudad, Zaragoza, Institución Fernando el Católico, pp. 133-168.

Del Camino Martínez, Carmen (2008), La escritura carolina en la Península Ibérica, en Paleografía I: La escritura en España hasta 1250, Burgos, Universidad de Burgos, pp. 141-160.

Debiais, Vincent (2009), Messages de Pierre: la lecture des inscriptions dans la communication médiévale (XIII-XIV), Turnhout, Brepols.

Díaz y Díaz, Manuel C.; Moralejo, Serafín (eds.) (1995), Libro de horas de Fernando I de León, Santiago de Compostela, Xunta de Galicia.

Diego Santos, Francisco (1995), Inscripciones medievales de Asturias, Oviedo, Gobierno del Principado de Asturias.

Dietl, Albert (2008), Die Sprache der Signatur. Die mittelalterlichen Künstlerinschriften Italiens (Italienische Forschungen des Kunsthistorischen), München - Berlin, Deutscher Kunstverlag Gmbh.

Duro Peña, Emilio (1977), El monasterio de San Esteban de Ribas de Sil, Orense, Instituto de Estudios Orensanos Padre Feijoo.

Fernández Flórez, José Antonio (2016), Escribir en los monasterios altomedievales del Occidente Peninsular (siglos VIII-XII), en Lugares de escritura: el monasterio, Alicante, Universidad de Alicante, pp. 17-69.

Fernández García, Patricio Manuel (2003), La memoria epigráfica del monasterio de Santa Cristina de Ribas de Sil: sus inscripciones medievales, "Boletín auriense" 33, pp. 185-208.

Fernández García, Patricio Manuel (2020), Corpus inscriptionum Hispaniae mediaevalium, 7. Orense, León, Universidad de León.

Fernández Suarez, Elisa (1978), El monasterio de Santa Cristina de Ribas de Sil, "Boletín Auriense" 8, pp. 7-22.

García Guinea, Miguel Ángel; Pérez González, José María (coords.) (2007), Enciclopedia del románico en Cantabria, Aguilar de Campoo, Fundación Santa María la Real - Centro de Estudios del Románico.

García Lobo, Vicente (1979), El beato de San Miguel de Escalada, "Archivos Leoneses" 66, pp. 205-270. 
García Lobo, Vicente (1982), Las inscripciones de San Miguel de Escalada, estudio crítico, Barcelona, El Albir.

García Lobo, Vicente (1999), La escritura publicitaria en la Península Ibérica, siglos X al XIV, en Inschrift und Material. Inschrift und Buchschrift. Fachtagung für mittelalterliche und neuzeitliche Epigraphik Ingolstadt 1997, Múnich, Verlag der Bay - Akademie der Wissenschaften, pp. 229-256.

García Lobo, Vicente (2001), De epigrafía medieval. Cuestiones de método: Centenario de la Cátedra de "Epigrafía y Numismática" Universidad Complutense de Madrid 1900/01-2000/01, Madrid, Universidad Complutense de Madrid.

García Lobo, Vicente (2002), Epigrafía palentina del Románico, en Palencia en los siglos del Románico, Aguilar de Campoo, Fundación Santa María La Real, pp. 239-265.

García Lobo, Vicente (2008), La escritura visigótica I: inscripciones y códices, en Paleografía I. La escritura en España hasta 1250, Burgos, Universidad de Burgos, pp. 61-91.

García Lobo, Vicente (2011), El difunto reivindicado a través de las inscripciones, en IX Jornadas Científicas sobre Documentación: la muerte y sus testimonios escritos, Madrid, Universidad Complutense de Madrid, pp. 171-198.

García Lobo, Vicente; Martín López, María Encarnación (1995), Errores de rogatario en una inscripción del siglo XII. (A propósito de les inscriptions du calice et de la patène de l'abbé Pelage au Louvre de Robert Favreau), "Estudios Humanísticos" 17, pp. 151-161.

García Lobo, Vicente; Martín López, María Encarnación (1996a), De epigrafía medieval. Introducción y álbum, "Cistercium: Revista cisterciense" 204, pp. 159-161.

García Lobo, Vicente; Martín López, María Encarnación (1996b), Las suscriptiones: relación entre el epígrafe y la obra de arte, en Épigraphie et iconographie. Actes du Colloque tenu à Poitiers les 5-8 octobre 1995, Poitiers, CESCM, pp. 75-99.

García Morilla, Alejandro (2014), Talleres, scriptoria y pequeños centros: la producción epigráfica en la provincia de Burgos, "Documenta \& Instrumenta" 12, pp. 145-194.

García Morilla, Alejandro (2016), Corpus inscriptionum Hispaniae mediaevalium. 1. Burgos, León, Universidad de León.

García Morilla, Alejandro (2018), La escritura publicitaria de transición, entre la visigótica y la carolina, "Espacio Tiempo Forma, serie III, historia medieval" 31, pp. 271-302. 
Gómez Moreno, Manuel (1966), Documentación goda en pizarra, Madrid, Real Academia de la Historia.

González de Fauve, María Estela (1992), El monasterio de Santa María de Aguilar de Campoo (siglos XI-XV), Aguilar de Campoo, Fundación Santa María La Real.

Gordon, Joyce; Gordon, Arthur (1957), Contributions to the palaeography of Latin Inscriptions, Berkeley, University of California Press.

Gutiérrez, Maximino (1995), Corpus Inscriptionum Hispaniae Mediaevalium, Zamora, 2 vols., León, Universidad de León.

Gutiérrez López, Bertín (2000), La Colegiata de San Martín de Elines, Burgos, Editur.

Herrero de la Fuente, Marta; Fernández Flórez, José Antonio (2012), Sobre la escritura visigótica en León y Castilla durante su etapa primitiva (siglos VII-X): algunas reflexiones, en La escritura visigótica en la Península Ibérica: nuevas aportaciones, Bellaterra, Universitat Autònoma de Barcelona, pp. 55-104.

Koch, Walter (2007), Inschriften paläographie des abendländischen Mittelalters und der früheren Neuzeit: Früh und Hochmittelalter, Viena, Oldenbourg Historische Hilfswissenschaften.

Mallon, Jean (1952), Paléographie romaine, Madrid, CSIC.

Martín López, María Encarnación (2007), Centros escriptorios epigráficos en la provincia de Palencia, en De Litteris, manuscriptis, inscriptionibus...Festcshrift zum 65. Geburtstag von Walter Koch, Viena, Böhlau, pp. 203-227.

Martín López, María Encarnación (2017), Du livre à la Pierre: l'écriture dans les inscriptions gothiques, "In-Scription-Livraisons" [en línea], http://in-scription.edel.univ-poitiers.fr/index.php?id=141 [consulta: 10/09/2018].

Martín López, María Encarnación (2018), Visibilidad de las clases no privilegiadas, en Escritura y Sociedad: burgueses, artesanos y campesinos, Madrid, Dickinson, pp. 9-40.

Martín López, María Encarnación; García Lobo, Vicente (coords.) (2010), Las inscripciones góticas. II Coloquio Internacional de Epigrafía Medieval, León del 11 al 15 de septiembre 2006, León, Corpus Inscriptionum Hispaniae Mediaevalium.

Martín Postigo, María Soterraña (1972), Un códice y una inscripción. El Beatus Silense (ss. XI-XII). La inscripción de S. Frutos (a. 1110), "Hispania Sacra" 25, pp. 209-225.

Marqués, José (2007), Dois casos de introduçao da escrita carolina e de resistência da visigótica: Guinimaraes e S. Simao da Junqueira, en 
Estudios en memoria del profesor Dr. Carlos Sáez, Alcalá de Henares, Universidad de Alcalá de Henares, pp. 109-124.

Millares Carlo, Agustín (1983), Tratado de Paleografía Española, 3 vols., Madrid, Espasa Calpe ( $3^{\text {a }}$ edición).

Molina de la Torre, Francisco Javier (2018), Corpus Inscriptionum Hispaniae Mediaevalium, 3. Valladolid, León, Universidad de León.

Navascués, Joaquín María de (1953), El concepto de Epigrafía. Consideraciones sobre la necesidad de su ampliación, Madrid, Real Academia de la Historia.

Ostolaza Elizondo, Isabel (1990), La transición de la escritura visigótica a la carolina en los monasterios del reino de León, en Actas del VII coloquio del comité internacional de paleografía latina, Madrid, Joyas Bibliográficas, pp. 149-164.

Peña Fernández, Alberto (2002), Epigrafía medieval en Campoo, "Cuadernos de Campoo" 29, pp. 17-25.

Peña Fernández, Alberto (2009), Epitafio de Munio: una inscripción del siglo XI en Santa María de Bareyo (Cantabria), "Altamira. Revista del centro de estudios montañeses" 77, pp. 105-129.

Peña Fernández, Alberto (2019), Corpus Inscriptionum Hispaniae Mediaevalium, 5. Cantabria, León, Universidad de León.

Pereira García, Irene (2017), La epigrafía Medieval en España. Un estado de la cuestión, "Anuario de Estudios Medievales" 47/1, pp. 267302.

Reglero de la Fuente, Carlos (2008), Cluny en España. Los prioratos de la provincia y sus redes sociales, (1073-1270), León, Centro de Estudios e Investigación San Isidoro.

Rodríguez Suárez, Natalia (2010), Características gráficas de los talleres epigráficos rurales ligados a la pintura, en Paleografía II: Las escrituras góticas desde 1250 hasta la imprenta, Oviedo, Universidad de Oviedo, pp. 263-274.

Rodríguez Suárez, Natalia (2015), La escritura publicitaria en los beatos: el caso del Beato de Urgel, una primera aproximación, "Documenta \& Instrumenta" 13, pp. 183-196.

Ruiz Albi, Irene (2003), La reina doña Urraca (1109-1126). Cancillería y colección diplomática, León, Centro de Estudios e Investigación San Isidoro.

Ruiz Asencio, José Manuel (2008), Cronología de la desaparición de la escritura visigótica en los documentos de León y Castilla, en Actas de la IV jornadas de la Sociedad Española de Ciencias y Técnicas Historiográficas, Burgos, Universidad de Burgos, pp. 95-117. 
Saco Cid, Juan Luis (1990-1991), O epígrafe fundacional da colexiata de Santa María a Real de Xunqueira de Ambía, "Boletín auriense" 20 21, pp. 277-291.

Velázquez Soriano, Isabel (2000), Documentos de época visigoda escritos en pizarra (siglos VI-VIII), Turnhout, Brepols.

Velázquez Soriano, Isabel (2014), Epigrafia en la Hispania de época visigoda: nuevas perspectivas revisiones críticas y estudios, en Wisigothica: after M. C. Díaz y Díaz, Firenze, SISMEL - Edizioni del Galluzzo, pp. 307-328.

Vives, José (1942), Inscripciones cristianas de la España romana y visigoda, Madrid, CSIC.

Fecha de recepción del artículo: abril 2019

Fecha de aceptación y versión final: mayo 2020 